\title{
Smoking is Not, But Alcohol Intake is Associated with Present LBP - A Survey of 1404 Employees in a Japanese Medical Equipment Factory
}

\section{Koichiro Okuyama ${ }^{1^{\star}}$, Kido Tadato ${ }^{1}$, Naohisa Miyakoshi ${ }^{2}$ and Yoichi Shimada ${ }^{2}$}

${ }^{1}$ Department of Orthopedic Surgery, Akita Rosai Hospital, Odate, Japan

${ }^{2}$ Department of Orthopedic Surgery, Akita University School of Medicine, Akita City, Japan

"Corresponding author: Koichiro Okuyama, Department of Orthopedic Surgery, Akita Rosai Hospital, Odate, Japan, Tel: +81-0186-52-3131; Fax: 81-0186-52-3131; Email: gonn@akitah.johas.go.jp

Rec Date: November 06, 2017; Acc Date: November 10, 2017; Pub Date: November 15, 2017

Copyright: @ 2017 Okuyama K, et al. This is an open-access article distributed under the terms of the Creative Commons Attribution License, which permits unrestricted use, distribution, and reproduction in any medium, provided the original author and source are credited.

\begin{abstract}
Study Design: Observational study.

Objective: Understanding the associated factors with lower back pain (LBP) and implementing effective prevention strategies are crucial. If the modifiable associated risk factors are uncovered in working generations, potential saving costs for workers' care systems and society overall are highly anticipated. The purpose of the current cross-sectional survey is to identify a prevalence of present LBP of employed workers and to analyze modifiable risk factors associated with LBP in Japan.
\end{abstract}

Methods: One thousand four hundred and four employees were enrolled. Age, gender, body height and weight, work demands, smoking, alcohol intake, depressive mood (MCS/SF-36v2 less than 35), regular exercise and so forth were ascertained by a self-administration questionnaire. Associations between Pw-LBP (LBP for the present week) and these items were statistically evaluated $(P<0.05=$ significant).

Results: The overall prevalence of Pw-LBP was 27.6\%. The mean age, body weight, and BMI were significantly higher in the participants with Pw-LBP than without Pw-LBP. MCS/SF-36v2 was significantly lower in the participants with Pw-LBP than without Pw-LBP. In light and/or moderate work demands, and alcohol intake, the percentage of the participants with Pw-LBP was significantly higher than that without Pw-LBP. Alcohol intake had a statistically significant association with Pw-LBP.

Conclusion: In Japanese employed workers, the prevalence of Pw-LBP was 27.6\%. The findings disclosed that alcohol intake was a risk factor of PW-LBP of employed workers in Japan.

Keywords: Lower Back Pain (LBP); Smoking; Alcohol intake; Work demands; Depressive mood

\section{Introduction}

Lower back pain (LBP) is one of the most common health problems on the globe. It is reported that $50.9 \%$ to $69.9 \%$ of people have experienced LBP at some time in their lives [1]. In a large Internet research project conducted in Japan, $83.4 \%$ of 65,496 Japanese people claimed that they had experienced LBP, and $24.6 \%$ of them took sick leave because of LBP at some point in their lives [2]. LBP also affects a huge number of industrial workers, and results in reduced quality of life (QOL), absence due to sickness/illness, loss of workers' productivity, and finally high health care costs. In terms of medical and social economics, LBP's influence on working generations is a very heavy burden on many industrialized countries. In 2007, Matsui et al. reported that the lifetime prevalence of LBP among Japanese was $60.5 \%$ (63.7\% in men, $47.6 \%$ in women), and the point LBP was $29.9 \%$ (30.6\% in men, $26.9 \%$ in women) in 3,760 various physical workers whose mean age was 41.6 years (range, 19-66) [3]. In the United Kingdom alone, the upper estimated economic loss associated with LBP is over $£ 12.3$ billion annually [4]. LBP is also the most common reason for filing worker's compensation claims, and the second highest cause of sick leave in the USA [5]. There are a few reports about economic loss due to LBP in Japanese workers. Shinohara et al. demonstrated that 5,556 victims had suffered from accidental LBP as an occupational illness in 1994, and estimated that a patient treated for non-specific LBP needed approximately 530,000 yen for worker's compensation, and their averaged sick leave and recuperation duration were $2.7 \pm 0.5$ and $1.2 \pm 0.4$ months [6]. Furthermore, Japanese annual medical costs of work-related LBP were estimated at 82.14 billion yen in 2011, and it accounted for $9.8 \%$ of the entire medical cost of LBP in Japan [7]. LBP of working populations is a big burden in Japan as well as in other industrialized countries.

Not only orthopedic doctors, but also general physicians need to have comprehensive approaches in treating patients with LBP, especially when treating LBP of working generation to improve workers' productivity, their QOL, and reducing secondary medical costs. The etiology of LBP is being uncovered, but has not been fully disclosed. Although it still remains unclear which risk factors are causative or not, many studies imply possible risk factors associated with development of LBP. Understanding the risk factors of LBP and implementing effective prevention strategies are very important. There are some modifiable associated factors with LBP that can be reduced by effective intervention. If the modifiable associated factors are 
disclosed in the working population, primary care and educational programs could be recommended. Limitation or less exposure to the modifiable associated factors with LBP may also lead to improvement of workers' productivity, QOL and many other benefits. Finally, reducing medical costs for workers' care systems are highly expected. A few studies written on the associated factors with LBP of Japanese workers have been published in English, but they are not primarily focused on the modifiable associated factors in detail $[3,8]$. The relationship between specific beliefs and specific cognitive processes in LBP is not well known. In terms of diagnosing LBP, understanding onset timing, the developmental course, and symptomatic duration are very important, but they are subjectively reported based on patients' memories. Therefore, diagnostic uncertainty and recall bias in past cases of LBP are very controversial. Serbric and Pincus have found evidence of a relationship between diagnostic uncertainty and recall bias for negative health-related stimuli in patients with chronic LBP, whose symptomatic duration were at least 3 months [9]. In the current survey, a prevalence of present LBP was investigated to avoid the participants' uncertain recollection of pain in the past. The purpose of the current cross-sectional research is to identify a prevalence of LBP for the present week (Pw-LBP) and to analyze modifiable factors associated with Pw-LBP among employees of a medical equipment factory in Japan.

\section{Material and Methods}

This survey was approved by the Ethics Committee of Akita Rosai Hospital according to the 1964 Helsinki Declaration. The approval number was 32. A medical equipment factory in Odate, Akita Prefecture, Japan cooperated with the current survey. The factory is one of the biggest medical equipment companies in Japan, and has the largest number of stably employed workers.

\begin{tabular}{|c|c|}
\hline Birthday & -- \\
\hline Gender (Male, Female) & -- \\
\hline Body height $(\mathrm{cm})$ and weight $(\mathrm{kg})$ & -- \\
\hline What type of job do you perform in this medical factory? & -- \\
\hline Do you smoke? & Yes/No \\
\hline \multicolumn{2}{|l|}{ If 'yes,' how many cigarettes do you smoke per day? } \\
\hline \multirow{4}{*}{ Do you drink? } & Never \\
\hline & Hardly Ever \\
\hline & Often \\
\hline & Everyday \\
\hline \multicolumn{2}{|c|}{ If you answered 'often' or "every day," how many go* do you drink per day? } \\
\hline Do you regularly exercise? & Yes/No \\
\hline \multicolumn{2}{|l|}{ If 'yes,' what kind of exercise do you do? } \\
\hline Do you have lower back pain for the present week? & Yes/No \\
\hline \multicolumn{2}{|l|}{${ }^{*} \mathrm{~A}$ gou (unit $\mathrm{f}$ sake) $180 \mathrm{ml}$ : Containing 20 grams of alcohol } \\
\hline
\end{tabular}

Table 1: Contents of self -administration questionnaire.

The total number of the employees in the medical equipment factory was 1,489. A cross sectional study about modifiable risk factors and a prevalence of LBP was carried out. A questionnaire was delivered, and was collected from 1,452 out of 1,489 employees in November 2015 (Collection rate: 97.5\%). Forty-eight individuals who did not complete the full items of the questionnaire were excluded. Therefore, 1,404 employees were enrolled as participants. Age, gender, body height and weight, work demands, smoking status, alcohol intake, regular exercise rates, and mental condition were ascertained in the questionnaire (Table 1).

The participants whose BMI was 25 or more were considered obese. The types of work demands were defined according to the physical work demands proposed by Matsui et al. (Table 2) [3].

\begin{tabular}{|l|l|}
\hline Work Demands & Contents \\
\hline Sedentary work & Sitting all day long \\
\hline Light wort & Sitting work with some light manual work \\
\hline Moderate work & Standing work all day long without carrying heavy items \\
\hline Heavy work & Carrying a heavy item all day long \\
\hline & Driving a truck or a forklift, loading and unloading goods \\
\hline & Carrying items with body trunk twisting \\
\hline & Body trunk bending often during work \\
\hline
\end{tabular}

Table 2: Physical job demands of participants according to Matsui et al. [3].

The participants who drank 'often' and 'everyday' were considered as habitual alcohol drinkers. The mental component summary scoring system from Medical Outcome Study Short-Form 36-Health Survey Version $2^{\circ}$ (MCS/SF-36v2) was used for evaluation of the participants' mental conditions [10]. The participants with MCS/SF-36v2 35 or less were regarded as depressive $[11,12]$. Associations between Pw-LBP and these items were statistically evaluated. A license to use MCS/SF-36v2 in Japanese language was obtained from iHope International Company.

\section{Statistical Analysis}

The significant difference between participants with and without Pw-LBP was analyzed by the Mann-Whitney $U$ test for ordinal data, and by the chi-square test for nominal data. Each possible risk factor associated with Pw-LBP was evaluated by a multiple logistic regression analysis. All analysis was performed by the Statistical Package for the Bioscience (SPBS-ware Version 9.6).

\section{Results}

The prevalence of Pw-LBP in the whole participants was $27.6 \%$ (388/1404). There was no significant difference in the prevalence of Pw-LBP among each decade of the participants (Table 3). Participants' characteristics were summarized in Table 4 . The mean age, body weight, and BMI were significantly higher in the participants with $\mathrm{Pw}$ LBP than without Pw-LBP ( $\mathrm{P}=0.029,0.004,0.012)$. MCS/SF-36v2 was significantly lower in the participants with $\mathrm{Pw}-\mathrm{LBP}$ than without $\mathrm{Pw}-$ LBP $(\mathrm{p}<0.001)$. 
Page 3 of 5

\begin{tabular}{|l|l|l|l|}
\hline $\begin{array}{l}\text { Age (number } \\
\text { participants) }\end{array}$ & $\begin{array}{l}\text { No. of Pw-LBP } \\
(\%)\end{array}$ & $\begin{array}{l}\text { Odds ratio (95\% } \\
\text { Cl) }\end{array}$ & $\begin{array}{l}\text { P- } \\
\text { value }\end{array}$ \\
\hline $18-19(41)$ & $8(19.5)$ & $0.76(0.34-1.63)$ & 0.631 \\
\hline $20-29(430)$ & $104(24.2)$ & reference & - \\
\hline $30-39(260)$ & $73(28.1)$ & $1.22(0.86-1.73)$ & 0.257 \\
\hline $40-49(283)$ & $86(30.4)$ & $1.37(0.98-1.91)$ & 0.067 \\
\hline $50-59(380)$ & $115(30.3)$ & $1.36(1.00-1.86)$ & 0.052 \\
\hline $60(10)$ & $2(20.0)$ & $0.78(0.16-3.75)$ & 0.76 \\
\hline
\end{tabular}

*PW-LBP: lower back pain for the present week

Table 3: The prevalence of Pw-LBP in each decade of participants.

It was impossible to clearly distinguish participants between light and moderate work demands. No participants were engaged in heavy work demands. The percentages of participants engaged in light and/or moderate work demands and sedentary ones were divided into $75.8 \%$ $(1064 / 1404)$ and $24.2 \%(340 / 1404)$, respectively. In light and/or moderate work demands, the percentage of the participants with $\mathrm{Pw}$ LBP was significantly higher than that without Pw-LBP $(\mathrm{P}=0.037)$. The percentage of cigarette smokers was $36.3 \%$ (510/1404), and the mean number of cigarettes was $11.9 \pm 6.4$ per day. Among habitual smokers, the percentage of the participants with $\mathrm{Pw}$-LBP was significantly higher than that without Pw-LBP ( $\mathrm{P}=0.034)$. The percentage of the participants drinking alcohol was $52.8 \%$ (741/1404), and the mean dose of the alcohol intake was $23.4 \pm 37.4 \mathrm{~g}$ a day. In alcohol intake, the percentage of the participants with $\mathrm{Pw}$-LBP was significantly higher than that without Pw-LBP $(\mathrm{P}=0.015)$.

\begin{tabular}{|c|c|c|c|}
\hline \multirow[t]{2}{*}{ Variables } & $\begin{array}{l}\text { Pw-LBP* } \\
\text { positive }\end{array}$ & $\begin{array}{l}\text { Pw-LBP } \\
\text { negative }\end{array}$ & \multirow[t]{2}{*}{ p-value } \\
\hline & $(n=388)$ & $(n=1016)$ & \\
\hline Age - mean \pm SD & $39.7 \pm 12.5$ & $38.1 \pm 12.6$ & $0.029^{* *}$ \\
\hline Male - n. of participants (\%) & $303(78.4)$ & $774(76.2)$ & 0.389 \\
\hline Height - mean \pm SD & $168.5 \pm 8.2$ & $167.6 \pm 8.8$ & 0.071 \\
\hline Weight - mean \pm SD & $66.1 \pm 13.2$ & $63.9 \pm 12.7$ & $0.004^{\star *}$ \\
\hline $\mathrm{BMI}-$ mean $\pm \mathrm{SD}$ & $23.1 \pm 3.7$ & $22.8 \pm 6.1$ & $0.012^{* *}$ \\
\hline MCS/SF-36v2 - mean \pm SD & $41.3 \pm 9.3$ & $46.1 \pm 9.8$ & $<0.001^{* \star}$ \\
\hline $\begin{array}{l}\text { Light and/or Moderate Work } \\
\text { Demands- } \mathrm{n}(\%)\end{array}$ & $309(79.6)$ & $755(74.3)$ & $0.037^{* *}$ \\
\hline Cigarette Smoking - $\mathrm{n}(\%)$ & $158(40.7)$ & $352(34.6)$ & $0.034^{* *}$ \\
\hline Alcohol Intake - n (\%) & $226(58.2)$ & $515(50.7)$ & $0.015^{\star *}$ \\
\hline Regular Exercise - $\mathrm{n}(\%)$ & $76(19.6)$ & $227(22.3)$ & 0.262 \\
\hline \multicolumn{4}{|c|}{${ }^{*}$ Pw-LBP: lower back pain for the present week } \\
\hline${ }^{* *}$ Significant $<0.05$ & & & \\
\hline
\end{tabular}

Table 4: Characteristics of the participants.

The percentage of participants engaged regular exercise was $21.6 \%$ $(303 / 1404)$. In regular exercise, the percentage of the participants with

Pw-LBP was not significantly higher than that without Pw-LBP $(\mathrm{P}=0.262)$. Alcohol intake only had a significant association with $\mathrm{Pw}-$ LBP (OR: 1.290, 95\% CI 1.015-1.640, $\mathrm{P}=0.037$ ) (Table 5).

\begin{tabular}{|c|c|c|c|c|c|c|}
\hline Variables & $\begin{array}{l}\text { Coefficie } \\
\text { nt }(\beta)\end{array}$ & SE & $\begin{array}{l}\text { Wald } \\
x^{2}\end{array}$ & $\begin{array}{l}\mathrm{P} \\
\text { Value }\end{array}$ & $\begin{array}{l}\text { Odds } \\
\text { Ratio }\end{array}$ & $95 \% \mathrm{Cl}$ \\
\hline Intercept & -1.35289 & 0.1492 & - & - & - & - \\
\hline $\begin{array}{l}\text { Sedentary Work } \\
\text { 0/Others } 1\end{array}$ & 0.239941 & 0.1475 & 2.646 & 0.104 & 1.271 & $\begin{array}{l}0.952- \\
1.697\end{array}$ \\
\hline $\mathrm{BMI}<250 / \geq 251$ & 0.12566 & 0.1341 & 0.878 & 0.349 & 1.134 & $\begin{array}{l}0.872- \\
1.475\end{array}$ \\
\hline $\begin{array}{l}\text { Regular } \\
\text { Exercise } \\
\text { 0/Yes 1 No }\end{array}$ & -0.196781 & 0.1497 & 1.729 & 0.189 & 0.821 & $\begin{array}{l}0.613- \\
1.101\end{array}$ \\
\hline $\begin{array}{l}\text { Smoking } \quad \text { No } \\
\text { 0/Yes } 1\end{array}$ & 0.175761 & 0.1261 & 1944 & 0.163 & 1.192 & $\begin{array}{l}0.931- \\
1.526\end{array}$ \\
\hline $\begin{array}{l}\text { Alcohol } \quad \text { No } \\
\text { 0/Yes } 1\end{array}$ & 0.25471 & 0.1223 & 4.335 & 0.037 & 1.29 & $\begin{array}{l}1.015- \\
1.640\end{array}$ \\
\hline $\begin{array}{l}\text { MCS/SF-36v2 } \leq \\
350 />351\end{array}$ & $\begin{array}{l}0.036125 \\
7\end{array}$ & 0.0463 & 0.608 & 0.435 & 1.037 & $\begin{array}{l}0.947- \\
1.135\end{array}$ \\
\hline \multicolumn{7}{|c|}{ Statistically significant finding indicated in bold } \\
\hline & & & & & & \\
\hline
\end{tabular}

Table 5: ORs and $95 \%$ CIs for $\mathrm{Pw}-\mathrm{LBP}^{\star}$ in relation to modifiable factors.

\section{Discussion}

The definition of LBP is also very inaccurate and vague because the behavioral and educational backgrounds of the participants vary to some extent. As a type of LBP, Takahashi et al. defined LBP as a pain within the past month that was felt anywhere from the L2-3 interspace through the gluteal area, and lasted longer than 24 hours within the Japanese population [8]. The definition is certainly suitable for Japanese subjects but might not be for populations in other countries because of cultural and ethnical differences. Diagnostic uncertainty and recall bias for negative health-related stimuli in chronic LBP patient are also very controversial [9]. Therefore, to avoid the participants' uncertain recollection of LBP in the past, a prevalence of present LBP was investigated in the current survey. Totally, the current result has shown that a prevalence of Pw-LBP in the 1,404 Japanese employees, whose mean age of $38.8 \pm 12.8$ years, was $27.6 \%$. LBP is reported to develop by a disturbance of the various organs, including the intervertebral disc, facet joints, ligamentous tissue, nerve roots, vertebral bones, paravertebral muscles of the lumbar spine, the posterior horn of the spinal cord, and the brain (hypothalamus, periaqueductal gray and rostral ventromedial medulla) $[13,14]$. It is impossible to mention the origin of $\mathrm{Pw}$ - $\mathrm{LBP}$, because the origin of $\mathrm{Pw}$ LBP could not be neurologically and psychologically evaluated in the current survey. Our data also has a possibility to include both acute and chronic LBP. These are the weak points of the current survey. There are a huge number of reports analyzing predictors of LBP, especially, some authors have mentioned that modifiable associated factors, which are very closely related to lifestyle and employed status of workers, play an important role for LBP development. Restriction or 
less exposure to the modifiable associated factors with LBP may lead to improvement of workers' productivity, QOL and many other benefits.

Cigarette smoking was normally considered as one of the modifiable risk factors in the literatures. In 2005, Mustard et al. also demonstrated that LBP was associated with heavy smoking ( $\geq 10$ cigarette/day, OR $1.85,95 \%$ CI 1.10-3.10) in young adults in Ontario, Canada [15]. In 2010, Shiri et al. performed a meta-analysis about the association between smoking and LBP. They concluded that both current and former smokers have a higher prevalence and incidence of LBP than those that have never smoked although the association was fairly modest, and the association between current smokers and the incidence of LBP is stronger in adolescents than in adults [16]. Recently, a report mentioning an association between smoking, nicotine dependence and addiction to opioids in patients with chronic non-malignant pain was published. The $\mu$ opioid receptor may play a key role of the development of chronic LBP [17]. On the contrary, cigarette smoking had no association with the prevalence of Pw-LBP although the percentage of the participants with Pw-LBP (40.7\%) was significantly higher than that without Pw-LBP (34.6\%) in the current survey $(\mathrm{P}=0.034)$. It implies that cigarette smoking (mean dose: $11.9 \pm$ 6.4 cigarettes a day) has no influence on the prevalence of Pw-LBP in Japanese employees. Wai et al. have also reported through a systematic review that there is no evidence as to the efficacy of quitting smoking [18]. It still remains unclear whether smoking is a causative risk factor for LBP.

To our knowledge, there are a few articles about the association between alcohol intake and LBP. In 2014, Nakamura et al. reported that alcohol consumption had an association with chronic musculocutaneous pain including LBP, and the OR is 1.32 (95\% CI 1.03 - 1.69. $\mathrm{p}=0.031$ ) among 11,507 Japanese participants [19]. In 2013, Ferreira et al. performed a systematic review of 26 articles that investigated alcohol intake and its association with LBP. Their review demonstrated that the pooled OR of the cross-sectional studies for the association between alcohol consumption and LBP was 1.3 (95\% CI 1.1 to 1.5). They concluded that this association was mild and not consistent across studies; furthermore, the relationship between alcohol consumption and LBP is important only in people with alcohol dependence and complex/chronic LBP. Unfortunately, they do not mention specific alcohol intake doses [20]. The result of the current survey is similar to the analysis of Ferreira et al. in that alcohol intake with a mean dose of $23.4 \pm 37.4 \mathrm{~g}$ a day has a mild association with Pw-LBP, but no detailed information of alcohol consumption dependence was obtained among the participants. The mechanism of alcohol intake to Pw-LBP is still unknown. The psychosocial factors due to dissatisfaction of working situation, a dead-end job and/or boredom are associated with chronic musculocutaneous pain, and there is a possibility that the psychosocial factors play crucial roles in alcohol consumption of working generations as well [19]. Contrarily, in 2016, Hestbaek el al. reported by a longitudinal study that there was a minor negative association between alcohol intake and persistent LBP among young twin adults (the OR: 0.74 ; 95\% CI 0.58-0.94) [21]. Further studies by a highly qualified methodology are necessary to disclose whether alcohol intake is a causative risk factor for LBP or vice versa.

In 2002, Guo et al. reported that the number of hours spent on repeated activities at work was associated with the presence of LBP, and that male carpenters, female nursing aides, orderlies and attendants had the highest prevalence of LBP. They have also proposed that measures should be taken to reduce repeated motions as well as bending, twisting, and reaching in the work place to decrease LBP [22]. Hartvigsen et al. also have concluded that physical workload might be more important than genetic factors in LBP [23]. In the current survey, the percentage of participants with Pw-LBP (79.6\%) was significantly higher than that without Pw-LBP (74.3\%) in the light and/or moderate work demands $(\mathrm{p}=0.037)$, but the light and/or moderate work demands did not have an association with Pw-LBP due to sedentary conditions. It is speculated that the light and/or moderate work demands did not require heavy lifting, trunk twisting, or bending body of the participants in the medical equipment factory.

In the current survey, the BMI were significantly higher in the participants with Pw-LBP than without Pw-LBP ( $\mathrm{p}=0.012$ ), but the average BMI of the participants was $22.5 \pm 5.9 \mathrm{~kg} / \mathrm{m}^{2}$, and there were no obese participants whose BMI was over 30 . The total participants were relatively healthy in terms of BMI. This fact may explain the reason that no obese associations with LBP were found in the current survey. In 2009, Alkherayf et al. reported an association between obesity (BMI $\geq 30$ ) and chronic LBP in 73,507 Canadians aged 20 to 59 years [24]. Hestbaek el al. reported no association between overweight and LBP in young monozygotic twins (22 years old and below) [21]. Regular exercise did not have a positive association with Pw-LBP in the current survey, and the result is limited due to the lack of detailed information about regular exercise. Wai et al. have summarized there is moderate evidence that physical activity combined with general aerobic and strengthening exercise or aqua fitness is more effective than non-active controls in disability due to chronic LBP. Additionally, there is limited evidence that physical activity combined with home aerobics is more effective than non-active controls for improvement in the worst LBP cases [18]. In a study conducted among young Finnish adults (age: 24-39), it was also concluded that both obesity and low levels of physical activity are independent risk factors of radiating LBP, and the authors recommended moderate levels of physical activity for the prevention of LBP [25].

Depression is a common co-morbidity for patients with LBP. However, depressive symptoms are not easily detected and often missed. Undiagnosed depressed patients do not gain proper reference and treatment that may reduce their total illness burden. The delayed diagnosis of depression results in increased medical costs, less productivity and an unsatisfied QOL of employed workers. It is very difficult for orthopaedic doctors, not for psychiatrist, to distinguish intrinsic depression from depressive mood in patients with LBP. Meanwhile, MCS/SF-36v2 is an easier and more valid predictor to detect subclinical depressive disorders rather than anxiety disorders in working populations with LBP [11]. A MCS/SF-36v2 35 or less, which is a cutoff point of depressive symptoms, was used because it has a sensitivity of $80 \%$ a specificity of $90 \%$, a ROC area of 0.8751 , and it correctly identified $87 \%$ of the samples [12]. In the current survey, MCS/SF-36v2 was significantly lower in the participants with Pw-LBP than those without Pw-LBP $(\mathrm{p}<0.001)$. But no associations were found between depressive mood (MCS/SF-36v2 35 or less) and Pw-LBP. In 2016, Pinheiro et al. carried out a systematic review, and reported that 11 of 17 articles demonstrated symptoms of depression at baseline that were related to worsening LBP outcomes, and the OR ranged 10.4 to 2.47 [26]. The current result is not completely against the report of Pinheiro et al. It is unclear whether the participants with MCS/SF-36v2 35 or less have intrinsic depression or not. The further investigation is very crucial to detect whether the depressive mood, including intrinsic depression is causative or vice versa to a prevalence of LBP. 
Citation: Okuyama K, Tadato K, Miyakoshi N, Shimada Y (2017) Smoking is Not, But Alcohol Intake is Associated with Present LBP - A Survey of 1404 Employees in a Japanese Medical Equipment Factory. J Spine 6: 395. doi:10.4172/2165-7939.1000395

Page 5 of 5

\section{Conclusion and Major Limitations}

- The overall prevalence of Pw-LBP was $27.6 \%$. Alcohol intake is only associated with Pw-LBP in Japanese employees.

- The participants subjectively reported their Pw-LBP. The causes, duration, and the severity of Pw-LBP could not be analyzed. Therefore, it still remains unknown whether a causal relationship between alcohol intake and LBP is present or not.

\section{Source of Funding}

This survey was financially supported as a dissemination project related to the occupational injuries and illness by Japanese Labor, Health and Welfare Organization in 2015-2016.

\section{References}

1. Anderson GB (1999) Epidemiological feature of chronic low-back pain. Lancet 354: 581-585.

2. Fujii T, Ko M (2013) Prevalence of low back pain and factors associated with chronic disabled back pain in Japan. Eur Spine J 22: 432-438.

3. Matsui H, Maeda A, Tsuji H, Naruse Y (1997) Risk indicators of low back pain among workers in Japan. Association of familial and physical factors with low back pain. Spine (Phila Pa 1976) 22: 1242-1248.

4. Maniadakis N, Gray A (2000) The economic burden of back pain in the UK. Pain 84: 95-103.

5. Klein BP, Jensen RC, Sanderson LM (1984) Assessment of workers' compensation claims for back strains/sprains. J Occup Med 26: 443-448.

6. Shinohara S, Okada M, Keira T, Ohwada M, Niitsuya M, et al. (1998) Prognosis of accidental low back pain at work. Tohoku J Exp Med 186: 291-302.

7. Ito H, Kitamura F, Yokoyama K (2013) Estimates of annual medical cost of work-related low back pain in Japan. Industrial Health 51: 524-529.

8. Takahashi N, Kikuchi S, Konno S, Morita S, Suzukamo Y, et al. (2006) Discrepancy between disability and the severity of low back pain: Demographic, psychologic, and employment-related factors. Spine (Phila Pa 1976) 31: 931-939.

9. Serbic D, Pincus T (2014) Diagnostic uncertainty and recall bias in chronic low back pain. Pain 155: 1540-1546.

10. Fukuhara S, Ware JE, Koshinski M, Wada S, Grandek B (1998) Psychometric and clinical tests of validity of the Japanese SF-36 health survey. J Clin Epidemiol 51: 1045-1053.

11. Silveira E, Taft C, Sundh V, Waern M, Palsson S, et al. (2005) Performance of the SF-36 health survey in screening for depressive and anxiety disorders in elderly female Swedish population. Qual Life Res 14: 1263-1274.
12. Walsh TL, Homa K, Hanscom B, Lurie J, Sepulveda MG, et al. (2006) Screening for depressive symptoms in patients with chronic spinal pain using SF-36 health survey. Spine J 6: 316-320.

13. Boos N, Rieder R, Shade V, Sparatt KF, Semmer N, et al. (1995) The diagnostic accuracy of magnetic resonance image, work perception, and psychosocial factors in identifying symptomatic disc herniations. Spine (Phila Pa 1976) 20: 2613-2625.

14. Eippert F, Bingel U, Schoell ED, Yacubian J, Kilinger R, et al. (2009) Activation of the opioidergic descending pain control system underlies placebo analgesia. Neuron 63: 533-543.

15. Mustard CA, Kalcevich C, Frank JW, Boyle M (2005) Childhood and early adult predictors of risk of incident back pain: Ontario child health study 2001 follow-up. Am J Epidemiol 162: 779-786.

16. Shiri R, Karppinen J, Leino-Arjas P, Solovieva S, Viikari-Juntura E (2010) The association between smoking and low back pain: A meta-analysis. Am J Med 123: 87. e7-35.

17. Plesner K, Jensen HI, Højsted J (2016) Smoking history, nicotine dependence and opioid use in patients with chronic non-malignant pain. Acta Anaesthesiol Scand 60: 988-994.

18. Wai EK, Rodriguez S, Dagenais S, Hall H (2008) Evidence-informed management of chronic low back pain with physical activity, smoking cession, and weight loss. Spine J 8: 195-202.

19. Nakamura M, Nishiwaki Y, Ushida T, Toyama Y (2014) Prevalence and characteristics of chronic musculoskeletal pain in Japan: A second survey of people with or without chronic pain. J Orthop Sci 19: 339-350.

20. Ferreira PH, Pinheiro MB, Machado GC, Ferreira ML (2013) Is alcohol intake associated with low back pain? A systematic review of observational studies. Man Ther 18: 183-190.

21. Hestbaek L, Leboeuf-Yde C, Kyvik KO (2006) Are lifestyle-factors in adolescence predictors for adult low back pain? A cross-sectional and prospective study of young twins. BMC Musculoskeletal Disorders 7.

22. Guo HR (2002) Working hours spent on repeated activities and prevalence of back pain. Occup Environ Med 59: 680-688.

23. Hartvigsen J, Kyvik KO, Yde CL, Lings S, Bakketeig L (2003) Ambigous relation between physical workload and low back pain: A twin control study. Occup Environ Med 60: 109-114.

24. Alkherayf F, Agbi C (2009) Cigarette smoking and chronic low back pain in the adult population. Clin Invest Med 32: 360-367.

25. Shiri R, Solovieva S, Husgafvel-Pursiainen K, Telama R, Yang X, et al. (2013) The role of obesity and physical activity in non-specific and radiating low back pain: The young Finns study. Semin Arthritis Rheum 46: 640-650.

26. Pinheiro MB, Ferreira ML, Refshauge K, Maher CG, Ordoñana JR, et al. (2016) Symptoms of depression as a prognostic factor for low back pain: A systematic review. Spine J 16: 105-116. 